\title{
OPERATION FOR ACUTE TYPE A AORTIC DISSECTION IN OCTOGENARIANS: IS IT JUSTIFIED?
}

\author{
Eugenio Neri, $\mathrm{MD}^{\mathrm{a}}$ \\ Thomas Toscano, MD, $\mathrm{PhD}^{\mathrm{a}}$ \\ Massimo Massetti, MD \\ Gianni Capannini, $\mathrm{MD}^{\mathrm{a}}$ \\ Enrico Carone, $\mathrm{MD}^{\mathrm{a}}$ \\ Enrico Tucci, $\mathrm{MD}^{\mathrm{a}}$ \\ Francesco Diciolla, MD \\ Sabino Scolletta, MD \\ Rémy Morello, $\mathrm{PhD}^{\mathrm{b}}$ \\ Carlo Sassi, MD
}

For related editorial, see p. 202.
Background: With the progressive aging of Western populations, cardiac surgeons are faced with treating an increasing number of elderly patients. Controversy exists as to whether the expenditure of health care resources on the growing elderly populations represents a cost-effective approach to resource management. The potential to avoid surgery in patients with little chance of survival and poor quality of life would spare unnecessary suffering, reduce operative mortality, and enhance the use of scarce resources.

Methods: We reviewed the records of 24 consecutive patients aged 80 years or older (mean age 83 years, range 80-93 years) who underwent operations for acute type A dissection from 1985 through 1999. No patient with acute type A dissection was refused surgery because of age or concomitant disease. Seventeen patients were men. Preoperatively, none of the patients was moribund, although $66 \%$ had hemodynamic instability and $41 \%$ experienced cerebral ischemia. All patients had one or more associated pathologic conditions. Hospital mortality and morbidity models, based on our overall experience with 197 patients operated on for acute type A aortic dissection during the period of the study, were developed by means of multivariate logistic regression with preoperative and intraoperative variables used as independent predictors of outcome.

Results: Overall hospital mortality was $83 \%$. Intraoperative mortality was $33 \%$. All patients who survived the operation had one or more postoperative complications. Mean hospital stay was 37 days with a total of 314 days in the intensive care unit (average 19 days, median 17 days). None of the survivors (4 patients) discharged from the hospital was able to function independently and their survival at 6 months was $0 \%$. Statistical analysis of the overall experience with operations for type A acute aortic dissection confirmed that age in excess of 80 years is the most important independent patient risk factor associated with 30-day mortality and morbidity.

Conclusions: Operations for acute type A dissection performed on octogenarians involve increased hospital mortality and morbidity. Short-term survival is unfavorable and is associated with a poor quality of life. Without additional corroborative studies to endorse the present findings, the use of age as a parameter to limit access of patients to expensive medical resources remains an unsubstantiated concept. In the context of acute type A aortic dissection, however, the hypothesis that older patients should be denied such a complicated surgical intervention to conserve resources is supported by the presented data. (J Thorac Cardiovasc Surg 2001;121:259-67)
From the Istituto di Chirurgia Cardiovascolare, ${ }^{a}$ Universita' agli Studi di Siena, Unita' Operativa di Chirurgia dell' Aorta Toracica, Siena, Italy, and Département de l'Information Médicale, ${ }^{\mathrm{b}} \mathrm{CHU}$ Clemenceau, Université de Caen, Caen, France.

Received for publication Aug 24, 1999; revisions requested Jan 14, 2000; revisions received Sept 27, 2000; accepted for publication Sept 29, 2000.
Address for reprints: Eugenio Neri, MD, Istituto di Chirurgia Cardiovascolare Universita' agli Studi di Siena, Policlinico le Scotte, Viale M. Bracci, 53100 Siena, Italy (E-mail: euxneri@tin.itnerie@unisi.it).

Copyright @ 2001 by The American Association for Thoracic Surgery

0022-5223/2001 $\$ 35.00+0 \quad \mathbf{1 2 / 1 / 1 1 2 2 0 5}$

doi: $10.1067 / \mathrm{mtc} .2001 .112205$ 
W ith important demographic changes taking place in cardiac surgical practice, older patients are more frequently undergoing complex operations. ${ }^{1-4}$ Controversy exists as to whether the health care resources allotted to this patient subset represent a costeffective approach to attaining a meaningful quality of life. Published studies on elective coronary artery bypass grafting and valve surgery reveal that elderly patients should not be denied these procedures, although the treatment of older patients involves increased hospital mortality, morbidity, and longer hospital stays. ${ }^{1-3}$ Aortic dissection generally is an acute condition, and mortality from acute type A dissection remains high despite important advances in operative therapy. Recent reports indicate that age is a risk determinant of early results after the emergency repair of type A aortic dissection. 5,6 This study reviews our experience with a particular subset of patients, aged 80 years or older.

\section{Patients and methods}

Patients. We reviewed the records of 24 consecutive patients aged 80 years or older who underwent operations for acute type A dissection between July 15, 1985, and June 20, 1999. They represent $12 \%$ of 197 operations for acute type A aortic dissection performed in the same period.

The clinical characteristics of these patients, consisting of 17 men and 7 women, are presented in Table I. The mean age of patients was 83.8 years (median 83 years; range 80-93 years). All patients had associated diseases. On admission, no patient was moribund, requiring external chest compression for cardiopulmonary resuscitation, although $66 \%$ of patients had hemodynamic instability. No patient was unconscious on admission, although 10 patients had a preoperative stroke. Renal and respiratory insufficiency was present before dissection in $29 \%$ and $70 \%$ of patients, respectively. A total of $62 \%$ of patients had a reduction in renal function preoperatively, which was largely attributable to hemodynamic instability.

Myocardial ischemia was encountered in $50 \%$ of the patients, 3 of whom had undergone coronary bypass grafting in the past. Moderate to severe chronic cardiac failure was present before dissection in $37 \%$ of the subjects. Two patients who underwent elective coronary angiography 4 and 9 months, respectively, before the acute event underwent complete myocardial revascularization during the operation for aortic dissection. No patient was refused surgery because of age or concomitant disease.

On admission, all patients had severe coagulation disorders: platelet aggregation (aggregometry) and hemostasis (thromboelastography) were markedly reduced in all patients. In addition, variable degrees of thrombocytopenia, low levels of the thrombin inhibitor angiotensin III and coagulation factors (fibrinogen V, VII, VIII, and IX), and high levels of plasmin degradation of cross-linked fibrin (D-dimer) were measured.
All procedures were performed in an emergency situation within 18 hours after the initial onset of chest pain, and all patients were operated on within 2 hours of their arrival. The operative techniques used are summarized in Table II.

In 11 patients, the earliest of our series, the aorta was clamped and retrograde femoral perfusion was used throughout the procedure. The mean period of aortic crossclamping for these patients was 71 minutes and mean cardiopulmonary bypass (CPB) time was 130 minutes (range 70-215 minutes). In 13 patients, no clamp was used and repair was performed with an open technique under hypothermic circulatory arrest. Retrograde cerebral perfusion was used in $9(37.5 \%)$ patients. The left axillary artery was cannulated in 6 patients. The mean period of cooling for these patients was 37 minutes, with the mean circulatory arrest time being 32 minutes (range 24-62 minutes). The time for rewarming averaged 49 minutes. Mean CPB time was 178 minutes (range 152-275 minutes). Intraoperative flow assessment with the aid of transesophageal echocardiography was performed in $12(50 \%)$ patients. No patient had documented cerebral malperfusion during CPB.

From a pathologic point of view, a high incidence (54\%) of intimal tears located in the transverse arch was found; these were always associated with ruptured calcified atherosclerotic plaques. In all patients, histologic examination of aortic tissue specimens revealed diffuse microcalcification, inside and surrounding smooth muscle cells, associated with typical characteristics of cystic medial necrosis with mucoid degeneration (grade 3 or 4 medial degeneration).

Operative technique. All operations in this series (Table II) were performed through a median sternotomy according to previously described standard surgical techniques. ${ }^{7}$ In the last 13 consecutive patients, hypothermic circulatory arrest was a planned procedure to allow replacement of the ascending aorta by means of an open technique. Preoperative coagulation disorders were aggressively treated from the time of admission with the aid of blood bank products, antithrombin III, aprotinin, and coagulation factor concentrates. Continuous ultrafiltration during $\mathrm{CPB}$ was routinely used, as was a Cell Saver device (Haemonetics Corp, Braintree, Mass). Arterial pressure monitoring lines were routinely placed on both radial arteries. Systemic anticoagulation for CPB was accomplished with heparin at an initial dose of 3 $\mathrm{mg} / \mathrm{kg}$ body weight. Adequate heparinization for CPB was assessed with the activated clotting time (Hemochron FTKACT; International Technidyne Corp, Edison, NJ), with further doses of heparin administered as required so as to maintain an activated clotting time greater than 750 seconds. At the end of the procedure, heparin was neutralized with protamine $(0.8 \mathrm{mg}$ of protamine per milligram of heparin). CPB was established with cardiac indices of 2.0 to $2.5 \mathrm{~L} \cdot \mathrm{min}^{-1}$. $\mathrm{m}^{-2}$. Cooling was stopped at $25^{\circ} \mathrm{C}$ in patients operated on with the crossclamp technique under moderate hypothermia. Arterial inflow adequacy was assessed clinically.

Transesophageal echocardiography is now routinely used for type A aortic dissections to detect malperfusion of the supra-aortic trunks on initiation of CPB. Myocardial protection is obtained with cold blood cardioplegic solution admin- 
Table I. Clinical data

\begin{tabular}{|c|c|c|c|}
\hline & \multicolumn{2}{|c|}{ Age } & \multirow[b]{2}{*}{$\mathrm{P}$ value } \\
\hline & $>80$ years & $<80$ years & \\
\hline No. of patients & 24 & 173 & - \\
\hline \multicolumn{4}{|l|}{ Clinical background } \\
\hline Mean age \pm SD (range) $(y)$ & $83 \pm 3.2(80-93)$ & $54 \pm 8.5(46-78)$ & $<.001$ \\
\hline Female & $7(29 \%)$ & $60(35 \%)$ & .59 \\
\hline Hypertension & $24(100 \%)$ & $154(89 \%)$ & .09 \\
\hline Smoking & $16(66 \%)$ & $58(33 \%)$ & .01 \\
\hline Diabetes & $7(29 \%)$ & $31(18 \%)$ & .19 \\
\hline Marfan syndrome & 0 & $19(11 \%)$ & .14 \\
\hline PVD & $16(66 \%)$ & $52(30 \%)$ & $<.001$ \\
\hline Abdominal aortic aneurysm & $4(16 \%)$ & $23(13 \%)$ & .65 \\
\hline Angina & $10(41 \%)$ & $57(33 \%)$ & .40 \\
\hline Renal insufficiency & $7(29 \%)$ & $47(27 \%)$ & .84 \\
\hline COPD & $17(70 \%)$ & $81(47 \%)$ & .03 \\
\hline Previous cardiac surgery & $4(16 \%)$ & $23(13 \%)$ & .65 \\
\hline Cardiac insufficiency & $9(37 \%)$ & $42(24 \%)$ & .17 \\
\hline \multicolumn{4}{|l|}{ Clinical presentation } \\
\hline Chest pain & $24(100 \%)$ & $173(100 \%)$ & - \\
\hline Hypotension & $16(66 \%)$ & $96(55 \%)$ & .30 \\
\hline Aortic valve regurgitation & $22(91 \%)$ & $149(86 \%)$ & .43 \\
\hline Pericardial effusion* & $22(91 \%)$ & $154(89 \%)$ & 69 \\
\hline Cardiac tamponade $\dagger$ & $15(62 \%)$ & $76(44 \%)$ & .09 \\
\hline CPR & 0 & $38(22 \%)$ & .01 \\
\hline Aortic rupture & $7(29 \%)$ & $28(16 \%)$ & .12 \\
\hline Myocardial ischemia & $8(33 \%)$ & $30(17 \%)$ & .08 \\
\hline Cerebral ischemia & $10(41 \%)$ & $42(24 \%)$ & .07 \\
\hline Oligoanuria & $15(62 \%)$ & $85(49 \%)$ & .22 \\
\hline Visceral ischemia & $7(29 \%)$ & $31(18 \%)$ & .27 \\
\hline Lower extremities ischemia & $7(29 \%)$ & $28(16 \%)$ & .12 \\
\hline Coagulation disorders & $15(62 \%)$ & $96(55 \%)$ & .52 \\
\hline \multicolumn{4}{|l|}{ Location of primary tear } \\
\hline Ascending aorta & $11(45 \%)$ & $151(87 \%)$ & $<.001$ \\
\hline Transverse arch & $13(54 \%)$ & $22(13 \%)$ & \\
\hline
\end{tabular}

$S D$, Standard deviation; $P V D$, peripheral vascular disease; $C O P D$, chronic obstructive pulmonary disease; $C P R$, cardiopulmonary resuscitation .

*Preoperative noninvasive diagnosis of pericardial effusion.

$\nmid$ Pericardial effusion with hemodynamic significance.

istered intermittently from the coronary ostia. Acid-base management during hypothermia is via an alpha-stat approach. Before hypothermic circulatory arrest, steroids are given routinely and the head is packed in ice to maintain cerebral hypothermia. Systemic cooling is considered adequate for hypothermic circulatory arrest when the nasopharyngeal temperature has reached $20^{\circ} \mathrm{C}$ and the bladder temperature is below $28^{\circ} \mathrm{C}$.

The postoperative hemostasis protocol used was derived from that proposed by Szefner ${ }^{8}$ and included tests for platelet function, for thrombin formation and its regulatory pathways, and for the fibrinolytic system. Treatments included administration of small doses of heparin, large doses of dipyridamole, modulated doses of aprotinin, pentoxifylline, and fresh frozen plasma, as well as fibrinogen and angiotensin III concentrates. Dosages were adapted to each patient's clinical profile, as well as to test interpretation criteria, to provide personalized treatment.
Statistical methods. Medical records of all 197 patients operated on for type A acute aortic dissection between July 15, 1985, and June 20, 1999, were reviewed, and a number of perioperative variables that were believed to have an impact on outcome were obtained (Tables I and II). Data were studied by descriptive and statistical analyses. SPSS application software version 10.0 (SPSS Inc, Chicago, Ill) was used for statistical analyses.

Significant differences between the two age groups (ie, younger than 80 years and 80 years or older) were assessed with univariate analysis (Tables I to III): categoric data were compared by means of the $\chi^{2}$ test or the Fisher exact test (as appropriate) and continuous variables with the Student $t$ test. Data were further analyzed by univariate and multivariate logistic regression with the response variable on the one hand being hospital mortality (30 days mortality) and on the other hand, morbidity (Appendixes 1 and 2). All variables with a zero or near-zero cell count were treated as continuous so that 
Table II. Operations

\begin{tabular}{lccc}
\hline & $\geq 80$ years & $<80$ years & P value \\
\hline $\begin{array}{l}\text { No. of patients } \\
\text { Distal procedure }\end{array}$ & 24 & 173 & \\
Ascending aortic replacement & $10(42 \%)$ & $40(23 \%)$ & .05 \\
Hemiarch replacement & $11(46 \%)$ & $96(55 \%)$ & .37 \\
Arch replacement & $3(12 \%)$ & $37(22 \%)$ & .42 \\
Proximal procedure & & & .06 \\
Aorto-aortic graft & $9(37 \%)$ & $35(20 \%)$ & .69 \\
Bentall procedure & $6(25 \%)$ & $37(21 \%)$ & .316 \\
Cabrol procedure & $2(8 \%)$ & .22 \\
Aortic valve resuspension & $7(29 \%)$ & .02 \\
Aortic crossclamping & $11(46 \%)$ & .32 \\
Mean myocardial ischemic time \pm SD (range) (min) & $71 \pm 27(45-118)$ & $73(42 \%)$ & .20 \\
Mean pump time \pm SD (range) (min) & $130 \pm 35(70-215)$ & $40(23 \%)$ & .01 \\
Open technique & $13(54 \%)$ & $65 \pm 33(43-127)$ & .68 \\
Mean circulatory arrest time \pm SD (range) (min) & $32 \pm 11(24-62)$ & $120 \pm 43(63-260)$ & .08 \\
Mean pump time \pm SD (range) (min) & $178 \pm 28(152-275)$ & $133(77 \%)$ & .26 \\
Retrograde cerebral perfusion & $9(37 \%)$ & $31 \pm 12(16-58)$ & .03 \\
Antegrade cerebral perfusion & 0 & $167 \pm 31(149-311)$ & \\
Associated procedures & & $46(27 \%)$ & \\
CABG & $2(8 \%)$ & $29(17 \%)$ & .60 \\
Mitral valve surgery & 0 & $17(10 \%)$ & $9(5 \%)$ \\
Abdominal aortic fenestration & 0 & $3(2 \%)$ & \\
\hline SD, Stan & & .00 \\
\hline
\end{tabular}

$S D$, Standard deviation; $C A B G$, coronary artery bypass grafting.

convergence was obtained. Multivariate models were applied to isolate the effect of each factor adjusted for all other factors: the .25 level $(P \leq .25)$ was used as a screening criterion for selection of candidate variables. So that problems created by multicolinearity could be avoided, variables that were too highly correlated among themselves were included at different times in different models. A backward procedure was used. A Wald $\chi^{2}$ test was used for testing the significance of individual coefficients. The results are shown as odds ratios with $95 \%$ confidence intervals.

\section{Results}

\section{Descriptive analysis}

Mortality. Overall hospital mortality was $83 \%$ (20 patients) (Table III). Intraoperative mortality was 33\% ( 8 patients). Intraoperative deaths included all 7 patients with preoperative visceral malperfusion and 4 of the patients with preoperative cerebral ischemia. Bleeding from coagulation disorders was the cause of death in $3(12 \%)$ patients, all of whom had undergone coronary bypass operations in the past. Fatal bleeding from surgical causes occurred in $2(8.3 \%)$ patients, the earliest of our series. The bleeding was due to the poor quality of the aortic tissue at the site of distal anastomosis in 1 patient and to the technique of repair in the other patient, with laceration of the aorta occurring at the site of aortic crossclamping.
Mortality for cardiac causes was 20\% (5 patients); 3 (12\%) patients could not be weaned from CPB because of intractable cardiac dysfunction and 2 died postoperatively of low cardiac output on postoperative days 9 and 16 , respectively. Only 1 patient had any evidence of acute myocardial infarction.

Permanent neurologic damage with cerebral death occurred in $4(16 \%)$ patients. Sepsis, complicated by multiorgan system failure (specifically, renal and respiratory failure), was the cause of death in 6 (25\%) patients.

Morbidity. All 16 patients who survived the operation had 1 or more postoperative complications (Table III). Immediate postoperative hemorrhage necessitating reoperation developed in $3(12 \%)$ patients. Multiple reoperations for bleeding were required in 3 other patients. Intravascular disseminated coagulation in its different phases was present in all patients from the time of admission. Despite aggressive management and routine blood coagulation tests, coagulation factor levels and fibrinolysis remained abnormal for the duration of $\mathrm{CPB}$ and at varying degrees after discontinuation of CPB. Factor V, factor VIII, fibrin degradation products, antithrombin III, D-dimer levels, and platelet counts were the most evident defects before, during, and after $\mathrm{CPB}$ and in the postoperative period.

Prolonged postoperative inotropic support for low cardiac output was required in $6(25 \%)$ patients. 
Table III. Complications

\begin{tabular}{lccc}
\hline & $\geq 80$ years $(n=24)$ & $<80$ years $(n=173)$ & P value \\
\hline Hospital mortality (30 days) & $20(83 \%)$ & $28(16 \%)$ & $<.0001$ \\
No complications & 0 & $118(68 \%)$ & $<.0001$ \\
One or more complications & $24(100 \%)$ & $55(32 \%)$ & $<.0001$ \\
Bleeding & & & .0001 \\
Intraoperative death & $6(25 \%)$ & $3(2 \%)$ & .008 \\
Reoperation & $6(25 \%)$ & $11(6 \%)$ & .24 \\
Cardiac failure & $6(25 \%)$ & $25(15 \%)$ & .11 \\
Prolonged inotropic support & $3(12 \%)$ & $7(4 \%)$ & .20 \\
Intraoperative death & $2(8 \%)$ & $5(3 \%)$ & $<.0001$ \\
Postoperative death (30 days) & $24(100 \%)$ & $39(23 \%)$ & $<.001$ \\
Infection & $6(25 \%)$ & $5(3 \%)$ & \\
Multiorgan failure/sepsis (death) & & & \\
Cerebral & $4(17 \%)$ & $12(7 \%)$ & .11 \\
Death & $6(25 \%)$ & $31(18 \%)$ & .41 \\
Permanent stroke & $9(37 \%)$ & $28(16 \%)$ & .02 \\
Hemodialysis & $8(33 \%)$ & $30(17 \%)$ & .09 \\
Prolonged respiratory support & & \\
Postoperative malperfusion & 0 & $3(2 \%)$ & 1.00 \\
Visceral & 0 & $7(4 \%)$ & .60 \\
Cerebral & & & \\
\hline
\end{tabular}

Respiratory failure necessitating tracheotomy for prolonged assisted ventilation occurred in 8 patients, of whom all but 2 died of sepsis before hospital discharge. All patients who survived the operation had infective complications. Fever with positive blood cultures (16 patients), lung infection (12 patients), urinary tract infection (4 patients), and sepsis (6 patients) was observed.

Stroke with neurologic damage complicated the postoperative course of $6(25 \%)$ patients. Preoperative cerebral ischemia was present in $10(41 \%)$ patients; of these, 4 died intraoperatively, 4 had permanent neurologic damage with cerebral death, and 2 partially recovered postoperatively. None of the patients, except for those with preoperative neurologic complications, had a postoperative neurologic deficit. Neurologic morbidity and mortality were negatively influenced by the operation, with variable degrees of worsening of the neurologic status in those patients who had preoperative cerebral ischemia. None of the patients had postoperative cerebral hemorrhage. Neurologic status was responsible for a marked reduction in functional independence in 2 of the 4 patients discharged from the hospital.

Nine (37\%) patients required hemodialysis treatment. The presence of renal failure in the postoperative period was associated with death in all but 1 of the patients. In 3 patients the development of renal failure was attributable to preoperative chronic renal insuffi- ciency, whereas in the others it was due to renal occlusive disease (1 patient), a massive blood transfusion (1 patient), and hemodynamic causes (4 patients).

The mean duration of hospital stay was 37 days with a total of 314 days in the intensive care unit (average 19 days, median 17 days).

Late mortality. Four of the surviving patients were discharged from the hospital. None of these patients was functionally independent. One patient died of cardiac tamponade 3 weeks after discharge. Two patients, who had preoperative moderate chronic obstructive pulmonary disease, required prolonged ventilatory weaning and were discharged from the intensive care unit after 32 and 44 days, respectively. Of these, 1 died of pneumonia 3 months after the operation and the other died of ventricular arrhythmia during rehospitalization for respiratory failure. One patient, who had postoperative renal failure, died of cardiac arrest during dialysis 5 months after the operation.

Statistical analysis. The two age groups examined (younger than 80 years and 80 years or older) were not significantly different from each other with respect to the majority of perioperative characteristics that are believed to have an impact on outcome in patients with type A acute aortic dissection (see Tables I and II). Despite this, the results are unequivocally poorer for the older age group (Table III). As indicated by univariate analysis (see Appendix 1A), perioperative patient variables correlated to operative mortality were 
age 80 years $(P<.0001)$, location of the primary tear in the aortic arch $(P<.001)$, peripheral vascular disease $(P=.01)$, preoperative visceral ischemia $(P=.01)$, aortic rupture $(P=.02)$, myocardial ischemia $(P=.02)$, and cardiac tamponade $(P=.05)$. For morbidity, univariate analysis indicated the following significant variables (Appendix 2A): age 80 years or older $(P<.0001)$, location of the primary tear in the aortic arch $(P=.001)$, preoperative cerebral ischemia $(P=.01)$, preoperative visceral ischemia $(P=.01)$, cardiac tamponade $(P=.045)$, preoperative myocardial ischemia $(P=.05)$, and repair without open technique $(P=.05)$. Mortality and morbidity models (Appendixes 1 and 2) based on multivariate logistic regression analysis confirmed that age (as a continuous variable) is by far the most important risk variable.

\section{Comment}

In recent years, technical improvements in emergency operations for acute aortic dissection, associated with better perioperative management and postoperative care of the patients, have resulted in an acceptable decline in hospital mortality rate.

In our institution, the results obtained in younger patients with type A acute aortic dissection (Tables I to III) confirm these achievements. The dismal outcome that we have observed in patients aged 80 years or older indicates that acute aortic dissection and the consequent operation further expose this population to the risk of complicated outcomes. Older patients have higher hospital mortality and more complications, even though preoperative differences between the two age groups are trivial. This is particularly the case for the variables found to be critical in the statistical models of mortality and morbidity elaborated in this study, with the exception of the higher prevalence of intimal tear in the aortic arch. The same models indicate that many perioperative factors traditionally associated with a poor outcome, such as stroke, renal insufficiency, previous cardiac surgery, cardiac insufficiency, and chronic obstructive pulmonary disease, do not serve here as predictors of mortality and morbidity, thus confirming the advances made in the management of patients with acute dissection. The critical influence of older age as the most important independent variable on the postoperative outcome is demonstrated by our study. From a statistical point of view, the variable "older age" condenses a variety of factors that are very difficult to categorize and quantify. These include physiologic and pathologic factors related to the normal degenerative processes of senescence that are beyond the control of the surgeon. As such, significant reductions in mortali- ty rates appear very difficult to achieve. Our study corroborates the hypothesis that acute type A aortic dissection in octogenarians goes beyond the limits of surgery, unlike other cardiac operations, which can be performed in elderly persons with a high risk but with a favorable long-term outcome., ${ }^{1,3}$

In this era of diminishing economic resources for health care, the question of whether such expensive surgical therapy should be offered to these patients is very relevant. Without the aid of specific studies to address this point in the context of acute type A aortic dissection, using age as a parameter to limit access of patients to resources remains an unsubstantiated concept, rather than a scientifically proven cost-saving measure. The hypothesis that older patients should be denied surgery to conserve resources is supported by the data presented here.

Society must always face the reality of limited medical resources and must find mechanisms for distributing these resources fairly and efficiently. In recent years, the focus for the evaluation of health services has shifted from unnecessary treatment, specifically unnecessary surgery, to the appropriateness of the treatment. Treatments that are extremely unlikely to be beneficial and are extremely costly may be considered inappropriate and hence inadvisable, but they should not be labeled futile. Three sources of value are defined that give meaning to "appropriateness" in patient care: the clinical point of view, the point of view of the individual patient, and the societal point of view. ${ }^{9}$ These concepts necessitate that the ethical and economic implications of medical services be integrated into outcome-based guidelines.

The aim of this study was to examine whether surgery for acute type A aortic dissection is beneficial to the elderly population. In light of the data presented, we conclude that such surgical treatment is inappropriate because it does not reverse the unfavorable prognosis of the disease.

Factors involved in the decision of withholding treatment are strongly influenced by ethical, social, and cultural considerations, as well as by national legislation. Whereas in some countries the public fears the specter of dying a protracted, dehumanizing, expensive death in the hospital as a result of the mindless application of complex technology, in others the request for maximal life support by the patient and family entourage make it impossible for surgery to be refused without inherent legal consequences. In all of these cases the surgeon is emotionally and ethically involved. As stated by Daniel J. Ullyot ${ }^{10}$ the appropriate application of technology begins early in the clinical encounter. Very often, in the 
presence of very ill and very "biologically old" subjects, what appears as inappropriate is to refer the patient for surgery. A surgical consultation offers the patient more than the simple agreement to do the procedure, because it creates expectations in the patient or the patient's family, making the decision to not operate extremely difficult. So that these difficulties can be overcome, practice guidelines based on scientific data need to be written. The present work aims to provide a small contribution to this commitment.

\section{REFERENCES}

1. Kirsch M, Guesnier L, LeBesnerais P, Hillion ML, Debauchez M, Seguin J, et al. Cardiac operations in octogenarians: perioperative risk factors for death and impaired autonomy. Ann Thorac Surg 1998;66:60-7.

2. Tsai TP, Matloff JM, Gray RJ, Chaux A, Kass RM, Lee ME, et al. Cardiac surgery in the octogenarian. J Thorac Cardiovasc Surg 1986;91:924-8

3. Tsai TP, Chaux A, Matloff JM, Kass RM, Gray RJ, DeRobertis MA, et al. 1 Ten-year experience of cardiac surgery in patients aged 80 years and over. Ann Thorac Surg 1994;58:445-50.
4. Girardi LN, Coselli JS. Repair of thoracoabdominal aortic aneurysms in octogenarians. Ann Thorac Surg 1998;65:491-5.

5. Aymard T, Rouviere P, Frapier JM, Demaria R, Albat B, Chaptal PA. Outcome of type I acute aortic dissection operated after 70 years of age: a retrospective study of operated dissection of the aorta in the over 70 years old. Arch Mal Coeur Vaiss 1998;91:239-43.

6. Ehrlich M, Fang WC, Grabenwoger M, Cartes-Zumelzu F, Wolner E, Havel M. Perioperative risk factors for mortality in patients with acute A aortic dissection. Circulation 1998;98(19 Suppl):II-294-8.

7. Borst HG. In: Borst HG, Heinemann MK, Stone CD, editors. Surgical treatment of aortic dissection. 1st ed. New York: Churchill Livingstone; 1996. p. 123-80.

8. Szefner J. Control and treatment of hemostasis in cardiovascular surgery: the experience of La Pitie Hospital with patients on total artificial heart. Int J Artif Organs 1995;18:633-48.

9. Consensus statement of the Society of Critical Care Medicine's Ethics Committee regarding futile and other possibly inadvisable treatments. Crit Care Med 1997;25:887-91.

10. Ullyot DJ. The assault on specialty medicine and the modern surgeon. J Thorac Cardiovasc Surg 1998;115:273-80.

Appendix 1A. Influence of perioperative risk factors on operative mortality: Univariate analysis

\begin{tabular}{|c|c|c|c|c|c|}
\hline \multirow[b]{3}{*}{ Risk factor } & \multicolumn{5}{|c|}{ Operative death } \\
\hline & \multirow{2}{*}{$\frac{\operatorname{Yes}(n=48)}{n}$} & \multirow{2}{*}{$\frac{N o(n=149)}{n}$} & \multicolumn{3}{|c|}{ Univariate analysis } \\
\hline & & & P value & Odds ratio & $95 \% C I$ \\
\hline Age $\geq 80$ & $20(41.7 \%)$ & $4(2.7 \%)$ & $<.001$ & 25.88 & $8.22-81.51$ \\
\hline Age (continuous variable) & - & - & $<.001$ & 1.06 & $1.03-1.08$ \\
\hline Sex: female (male) & $18(37.5 \%)$ & $49(32.9 \%)$ & .56 & 1.22 & $0.66-2.41$ \\
\hline Smoking: Y (N) & $19(39.6 \%)$ & $55(36.9 \%)$ & .74 & 1.12 & $0.57-2.18$ \\
\hline Hypertension: $\mathrm{Y}(\mathrm{N})$ & $45(93.8 \%)$ & $133(89.3 \%)$ & .37 & 1.80 & $0.50-6.48$ \\
\hline Diabetes: Y (N) & $11(22.9 \%)$ & $27(18.1 \%)$ & .46 & 1.34 & $0.61-2.96$ \\
\hline Peripheral vascular disease: $\mathrm{Y}(\mathrm{N})$ & $24(50.0 \%)$ & $44(29.5 \%)$ & .01 & 2.39 & $1.23-4.65$ \\
\hline Abdominal aortic aneurysm: $\mathrm{Y}(\mathrm{N})$ & $9(18.8 \%)$ & $18(12.1 \%)$ & .25 & 1.68 & $0.70-4.03$ \\
\hline Angina: Y (N) & $18(37.5 \%)$ & $49(32.9 \%)$ & .56 & 1.22 & $0.62-2.41$ \\
\hline Renal insufficiency: $\mathrm{Y}(\mathrm{N})$ & $14(29.2 \%)$ & $40(26.8 \%)$ & .75 & 1.12 & $0.55-2.31$ \\
\hline Chronic obstructive pulmonary disease: $\mathrm{Y}(\mathrm{N})$ & $29(60.4 \%)$ & $69(46.3 \%)$ & .09 & 1.77 & $0.91-3.43$ \\
\hline Previous cardiac surgery: $\mathrm{Y}(\mathrm{N})$ & $8(16.7 \%)$ & $19(12.8 \%)$ & .49 & 1.37 & $0.56-3.36$ \\
\hline Cardiac insufficiency: $\mathrm{Y}(\mathrm{N})$ & $14(29.2 \%)$ & $37(24.8 \%)$ & .55 & 1.25 & $0.60-2.57$ \\
\hline Hypotension at admission: $\mathrm{Y}(\mathrm{N})$ & $31(64.6 \%)$ & $81(54.4 \%)$ & .21 & 1.53 & $0.78-3.00$ \\
\hline Aortic valve regurgitation: $\mathrm{Y}(\mathrm{N})$ & $43(89.6 \%)$ & $128(85.9 \%)$ & .51 & 1.41 & $0.50-3.97$ \\
\hline Cardiac tamponade: $\mathrm{Y}(\mathrm{N})$ & $28(58.3 \%)$ & $63(42.3 \%)$ & .05 & 1.91 & $0.99-3.69$ \\
\hline Cardiopulmonary resuscitation: $\mathrm{N}(\mathrm{Y})$ & $6(12.5 \%)$ & $32(21.5 \%)$ & .18 & 0.52 & $0.20-1.34$ \\
\hline Aortic rupture: $\mathrm{Y}(\mathrm{N})$ & $14(29.2 \%)$ & $21(14.1 \%)$ & .02 & 2.51 & $1.16-5.45$ \\
\hline Myocardial ischemia: $\mathrm{Y}(\mathrm{N})$ & $15(31.3 \%)$ & $23(15.4 \%)$ & .02 & 2.49 & $1.17-5.30$ \\
\hline Cerebral ischemia: $\mathrm{Y}(\mathrm{N})$ & $18(37.5 \%)$ & $34(22.8 \%)$ & .047 & 2.03 & $1.01-4.08$ \\
\hline Oligoanuria: $\mathrm{Y}(\mathrm{N})$ & $29(60.4 \%)$ & $71(47.7 \%)$ & .13 & 1.68 & $0.86-3.25$ \\
\hline Visceral ischemia: $\mathrm{Y}(\mathrm{N})$ & $16(33.3 \%)$ & $22(14.8 \%)$ & .01 & 2.89 & $1.37-6.12$ \\
\hline Coagulation disorders: $\mathrm{Y}(\mathrm{N})$ & $29(60.4 \%)$ & $82(55.0 \%)$ & .51 & 1.25 & $0.64-2.42$ \\
\hline Primary tear in the arch: $\mathrm{Y}(\mathrm{N})$ & $17(35.4 \%)$ & $18(12.1 \%)$ & $<.001$ & 3.99 & $1.85-8.62$ \\
\hline Repair without open technique: $\mathrm{Y}(\mathrm{N})$ & $15(31.3 \%)$ & $36(24.2 \%)$ & .33 & 1.43 & $0.70-2.92$ \\
\hline
\end{tabular}

$Y$, Yes; $N$, no; $95 \% C I$, 95\% confidence intervals. 
Appendix 1B. Influence of perioperative risk factors on operative mortality: Multivariate analysis*

\begin{tabular}{|c|c|c|c|}
\hline & & Odds ratio & $95 \% C I$ \\
\hline \multicolumn{4}{|l|}{ Logistic regression $\dagger$} \\
\hline \multirow[t]{2}{*}{ Visceral ischemia } & No & 1 & \\
\hline & Yes & 6.21 & $2.23-17.35$ \\
\hline \multirow[t]{2}{*}{ Cardiopulmonary resuscitation } & Yes & 1 & \\
\hline & No & 5.39 & $1.61-18.04$ \\
\hline \multirow{2}{*}{ Myocardial ischemia } & No & 1 & \\
\hline & Yes & 2.93 & $1.24-6.90$ \\
\hline Age (continuous variable) & - & 1.05 & $1.03-1.08$ \\
\hline \multicolumn{4}{|l|}{ Logistic regression $\neq$} \\
\hline \multirow[t]{2}{*}{ Aortic rupture } & No & 1 & \\
\hline & Yes & 2.63 & $1.09-6.34$ \\
\hline \multicolumn{4}{|l|}{ Logistic regression§ } \\
\hline \multirow[t]{2}{*}{ Primary tear in the arch } & No & 1 & \\
\hline & Yes & 3.04 & $1.30-7.11$ \\
\hline
\end{tabular}

$95 \%$ CI, 95\% confidence intervals.

*After elimination of variables with $P$ value $>.05$ at multivariate logistic regression: sex, peripheral vascular disease, abdominal aortic aneurysm, chronic obstructive pulmonary disease, hypotension, cardiac tamponade, cerebral ischemia, and oligoanuria.

$\nmid$ Model including the following significant variables: visceral ischemia, cardiopulmonary resuscitation, myocardial ischemia, and age as a continuous variable. ¥Model including the following significant variables: visceral ischemia, cardiopulmonary resuscitation, aortic rupture, and age as a continuous variable.

\$Model including the following significant variables: visceral ischemia, repair without open technique, myocardial ischemia, and age as a continuous variable.

Appendix 2A. Influence of perioperative risk factors on morbidity: Univariate analysis

\begin{tabular}{|c|c|c|c|c|c|}
\hline & \multicolumn{5}{|c|}{ One or more complications } \\
\hline & \multirow{2}{*}{$\frac{\operatorname{Yes}(n=74)}{n}$} & \multirow{2}{*}{$\frac{N o(n=123)}{n}$} & \multicolumn{3}{|c|}{ Univariate analysis } \\
\hline & & & $\mathrm{P}$ value & Odds ratio & $95 \% C I$ \\
\hline \multicolumn{6}{|l|}{ Risk factor } \\
\hline Age $\geq 80$ & $24(32.4 \%)$ & $00(00.0 \%)$ & $<.001$ & - & - \\
\hline Age (continuous variable) & - & - & $<.001$ & 1.07 & $1.04-1.09$ \\
\hline Sex: female/male & $30(40.5 \%)$ & $37(30.1 \%)$ & .13 & 1.58 & $0.87-2.90$ \\
\hline Smoking: Y (N) & $29(39.2 \%)$ & $45(37.6 \%)$ & .71 & 1.12 & $0.62-2.02$ \\
\hline Hypertension: $\mathrm{Y}(\mathrm{N})$ & $70(94.6 \%)$ & $108(87.8 \%)$ & .13 & 2.43 & $0.77-7.62$ \\
\hline Diabetes: $\mathrm{Y}(\mathrm{N})$ & $15(20.3 \%)$ & $23(18.7 \%)$ & .79 & 1.10 & $0.53-2.28$ \\
\hline Peripheral vascular disease: $\mathrm{Y}(\mathrm{N})$ & $31(41.9 \%)$ & $37(30.1 \%)$ & .09 & 1.67 & $0.92-3.06$ \\
\hline Abdominal aortic aneurysm: $\mathrm{Y}(\mathrm{N})$ & $10(13.5 \%)$ & $17(13.8 \%)$ & .95 & 0.97 & $0.42-2.26$ \\
\hline Angina: $\mathrm{Y}(\mathrm{N})$ & $29(39.2 \%)$ & $38(30.9 \%)$ & .23 & 1.44 & $0.79-2.63$ \\
\hline Renal insufficiency: $\mathrm{Y}(\mathrm{N})$ & $23(31.1 \%)$ & $31(25.2 \%)$ & .37 & 1.34 & $0.71-2.53$ \\
\hline Chronic obstructive pulmonary disease: $\mathrm{Y}(\mathrm{N})$ & $41(55.4 \%)$ & $57(46.3 \%)$ & .22 & 1.44 & $0.81-2.57$ \\
\hline Previous cardiac surgery: $\mathrm{Y}(\mathrm{N})$ & $14(18.9 \%)$ & $13(10.6 \%)$ & .10 & 1.97 & $0.87-4.47$ \\
\hline Cardiac insufficiency: $\mathrm{Y}(\mathrm{N})$ & $19(25.7 \%)$ & $32(26.0 \%)$ & .96 & 0.98 & $0.51-1.90$ \\
\hline Hypotension at admission: $\mathrm{Y}(\mathrm{N})$ & $47(63.5 \%)$ & $65(52.8 \%)$ & .14 & 1.55 & $0.86-2.80$ \\
\hline Aortic valve regurgitation: $\mathrm{Y}(\mathrm{N})$ & $68(91.9 \%)$ & $103(83.7 \%)$ & .11 & 2.20 & $0.84-5.76$ \\
\hline Cardiac tamponade: $\mathrm{Y}(\mathrm{N})$ & $41(55.4 \%)$ & $50(40.7 \%)$ & .045 & 1.81 & $1.01-3.25$ \\
\hline Cardiopulmonary resuscitation: $\mathrm{Y}(\mathrm{N})$ & $12(16.2 \%)$ & $26(21.1 \%)$ & .40 & 0.72 & $0.34-1.54$ \\
\hline Aortic rupture: $\mathrm{Y}(\mathrm{N})$ & $16(21.6 \%)$ & $19(15.4 \%)$ & .27 & 1.51 & $0.72-3.16$ \\
\hline Myocardial ischemia: $\mathrm{Y}(\mathrm{N})$ & $22(29.7 \%)$ & $16(13.0 \%)$ & .005 & 2.83 & $1.37-5.84$ \\
\hline Cerebral ischemia: $\mathrm{Y}(\mathrm{N})$ & $27(36.5 \%)$ & $25(20.3 \%)$ & .01 & 2.25 & $1.18-4.29$ \\
\hline Oligoanuria: $\mathrm{Y}(\mathrm{N})$ & $43(58.1 \%)$ & $57(46.3 \%)$ & .11 & 1.61 & $0.90-2.87$ \\
\hline Visceral ischemia: $\mathrm{Y}(\mathrm{N})$ & $21(28.4 \%)$ & $17(13.8 \%)$ & .01 & 2.47 & $1.20-5.07$ \\
\hline Coagulation disorders: $\mathrm{Y}(\mathrm{N})$ & $48(64.9 \%)$ & $63(51.2 \%)$ & .06 & 1.76 & $0.97-3.18$ \\
\hline Primary tear in the arch: $\mathrm{Y}(\mathrm{N})$ & $22(29.7 \%)$ & $13(10.6 \%)$ & .001 & 3.58 & $1.67-7.66$ \\
\hline Repair without open technique: Y $(\mathrm{N})$ & $25(33.8 \%)$ & $26(21.1 \%)$ & .05 & 1.90 & $1.00-3.64$ \\
\hline
\end{tabular}

$Y$, yes; $N$, no; $95 \% C I$, $95 \%$ confidence intervals. 
Appendix 2B. Influence of perioperative risk factors on morbidity: Multivariate analysis*

\begin{tabular}{lccc}
\hline & & Odds ratio & $95 \%$ CI \\
\hline Logistic regression $\dagger$ & & & - \\
Primary tear in the arch & No & 1 & $1.71-8.29$ \\
& Yes & 3.77 & - \\
Myocardial ischemia & No & 1 & $1.41-6.42$ \\
& Yes & 3.01 & - \\
Aortic valve regurgitation & Ye & 3.12 & $1.06-9.19$ \\
Logistic regression $\neq$ & & 1.07 & $1.05-1.11$ \\
Age (continuous variable) & - & 1 & $1.19-4.83$ \\
Sex & Male & 2.39 & \\
\hline
\end{tabular}

$95 \%$ CI, 95\% confidence intervals.

*After elimination of variables with $P$ value $>.05$ at multivariate logistic regression: hypertension, peripheral vascular disease, angina, chronic obstructive pulmonary disease, previous cardiac surgery, hypotension, cerebral ischemia, oligoanuria, visceral ischemia, coagulation disorders, and repair without open technique.

$\dagger$ Model including the following significant variables: primary tear in the arch, myocardial ischemia, and aortic valve regurgitation.

¥odel including the following significant variables: myocardial ischemia, aortic valve regurgitation, sex, and age as a continuous variable.

\section{ON THE MOVE?}

Don't miss a single issue of the journal! To ensure prompt service when you change your address, please photocopy and complete the form below.

Please send your change of address notification at least six weeks before your move to ensure continued service. We regret we cannot guarantee replacement of issues missed due to late notification.

\section{JOURNAL TITLE:}

Fill in the title of the journal here.

\section{OLD ADDRESS:}

Affix the address label from a recent issue of the journal here.

\section{NEW ADDRESS: \\ Clearly print your new address here.}

Name

Address

City/State/ZIP

\section{COPY AND MAIL THIS FORM TO:}

Mosby

Subscription Customer Service

6277 Sea Harbor Dr

Orlando, FL 32887
OR FAX TO:

407-363-9661

N/ Mosby
OR PHONE:

800-654-2452

Outside the U.S., call

407-345-4000 